\title{
Heterocycles as versatile bulding blocks in different synthetic strategies
}

\author{
Amin F. M. Fahmy \\ Department of Chemistry, Faculty of Science and Science Education Center, \\ Ain Shams University, Abbassia, Cairo, Egypt \\ E-mail: Fahmy@online.com.eg
}

\begin{abstract}
Heterocycle-Heterocycle Synthetic Strategies (HHSS) were based on different types of reactions e.g. cycloaddition, cyclocondensation, molecular rearrangement, ANRORC. Spiro, condensed noncondensed, heterocycles were obtained via HHSS from easy one-pot reactions in moderate to high yields.
\end{abstract}

Keywords: Cyclimides, fused oxazines, fused pyrimidines, fused pyridazines, fused pyrans, fused thiopyrans

\section{Contents}

Introduction

1. Cyclic imides as building blocks

1.1. $N$-Hydroxyimides

1.2. $N$-Arylsulphonyloxy cyclic imides

2. Spirooxiranes as building blocks

2.1. 2-Aryl-1-oxaspiro $(2,5)$ octa-4-ones

2.2. 3'-Aryl-(3'H) $(2 H)$-spirooxirane $\left(2^{\prime}, 3\right)$-benzopyran-4-ones

3. Oxazines as building blocks

3.1. 2, 3-Benzoxazin-1-one

3.2. Benxoxazines and pyrido-oxazines

4. Pyridopyridazines as building blocks

5. Oxazolones as building blocks

6. Uracils as building blocks

7. Pyridazinones as building blocks

8. Benzopyran and benzothiopyran derivatives as building blocks

Acknowledgements

References 


\section{Introduction}

Heterocycles can offer elegant and efficient routes for building heterocyclic systems in different synthetic strategies including cycloaddition, cyclocondensation, molecular rearrangements, ANRORC, and ANRORC with molecular rearrangement. Imides, 1,3-oxazoles, uracils, 2,3oxazines, pyridazines, 2,3-benzoxazines, quinazolines, pyridopyridazines, benzopyranes, benzothiopyranes, and spirooxiranes were used as useful building blocks in different synthetic pathways for the synthesis of spiro, condensed, and noncondensed heterocyclic systems.

This lecture will present the context and background to our work in the area of synthetic heterocyclic chemistry. We illustrate the idea of heterocycle-heterocycle synthetic strategies (HHSS) in the following figure 1.

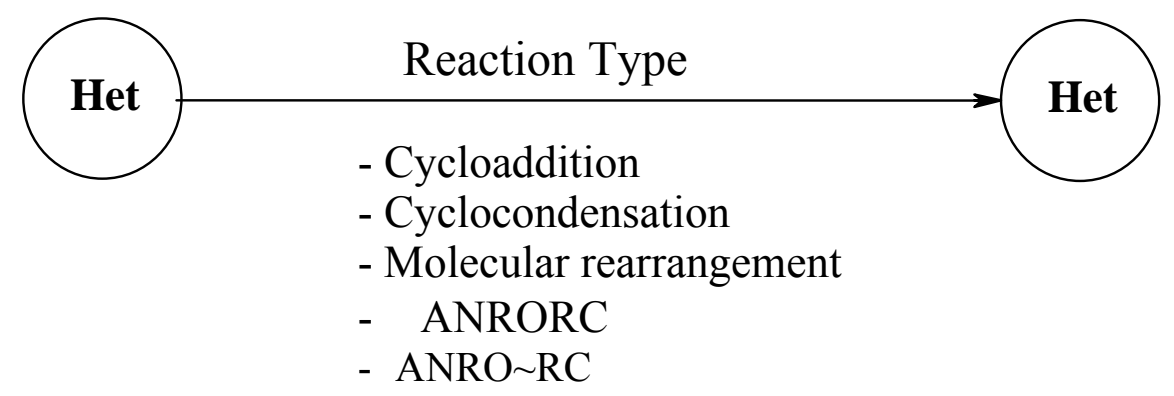

\section{Figure 1}

\section{Cyclic imides as building blocks}

In our studies on the HHSS, cyclic imides 1-2 were used as versatile building blocks in synthesis of different target heterocyclic systems, e.g. benzoxazines, pyridooxazines, quinazolines pyridopyrimidines.

Different building strategies were used based on ANRORC, ANRO RC, molecular rearrangement, cyclocondensation, and cycloaddation reactions.

Table 1. Cyclic imides

\begin{tabular}{|c|c|c|c|}
\hline 1 & $\mathbf{Y}$ & 2 & $\mathbf{Y}$ \\
\hline $\begin{array}{l}\mathrm{a} \\
\mathrm{b} \\
\mathrm{c}\end{array}$ & $\begin{array}{l}\text { - } \mathrm{OH} \\
-\mathrm{OSO}_{2}-\mathrm{C}_{6} \mathrm{H}_{5} \\
-\mathrm{OSO}_{2} \mathrm{C}_{6} \mathrm{H}_{4} \mathrm{CH}_{3}(\mathrm{P} .)\end{array}$ & $\begin{array}{l}\mathrm{d} \\
\mathrm{a}\end{array}$ & $\begin{array}{l}\mathrm{OH} \\
\mathrm{OSO}_{2}-\mathrm{C}_{6} \mathrm{H}_{5}\end{array}$ \\
\hline
\end{tabular}




\section{1. $N$-Hydroxyimides}

$N$-Hydroxyimides 1a, 2a can be used in synthesis of condensed oxazines via one - pot reaction. The reaction takes place via Lewis acid - catalyzed 1,3-acylmigration followed by Beckmann rearrangement.

$N$-Hydroxyphthalimide ${ }^{1}$ 1a reacts with anhydrous $\mathrm{AlCl}_{3}$ in aromatic substrates under reflux to give 4-aryl- $H$ [2, 3]-benzoxazin-1-ones ${ }^{1,2}$ 3a-d in $28-35 \%$ Yields.

Similarly, $N$-hydroxy-pyridine-2,3-dicarboxylic imides ${ }^{3}$ 2a reacts with anhydrous $\mathrm{AlCl}_{3}$ in aromatic substrates under the same reaction condition to give a mixture of two isomeric pyridooxazines, namely 8-arylpyrido[2,3-d][1,2]oxazin-5-ones 4a-d in 20-24\% yields, and 5arylpyrido-[3,2-d] [1,2] oxazin-8-ones 5a-c in $35-45 \%$ yields.

In the case of anisole a mixture of 8 -[4-anisyl] pyrido[2,3-d][1,2] oxazin-5-one $4 \mathbf{c}$, in $6 \%$ yield, and 5, 5-di-[4.anisyl]6-hydroxypyrrolo[3, 4-b]pyridine-7-one 6 was obtained in 49\% yield (Scheme 1).
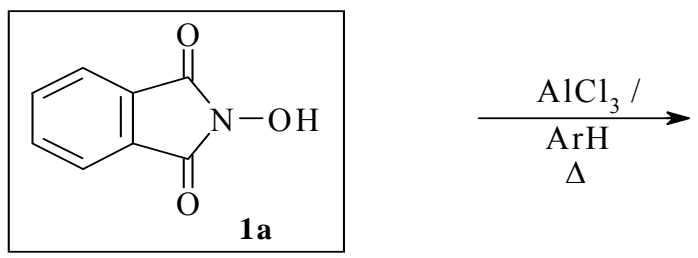<smiles>O=c1onc([AlH2])c2ccccc12</smiles>

\begin{tabular}{c|l} 
3 & \multicolumn{1}{|c}{$\mathbf{A r}$} \\
\hline $\mathrm{a}$ & $\mathrm{C}_{6} \mathrm{H}_{5}-$ \\
$\mathrm{b}$ & $4-\mathrm{CH}_{3} \mathrm{C}_{6} \mathrm{H}_{4}-$ \\
$\mathrm{c}$ & $4-\mathrm{CH}_{3} \mathrm{O} \mathrm{C}_{6} \mathrm{H}_{4}-$ \\
$\mathrm{d}$ & $4-\mathrm{Cl}_{6} \mathrm{H}_{4}-$
\end{tabular}
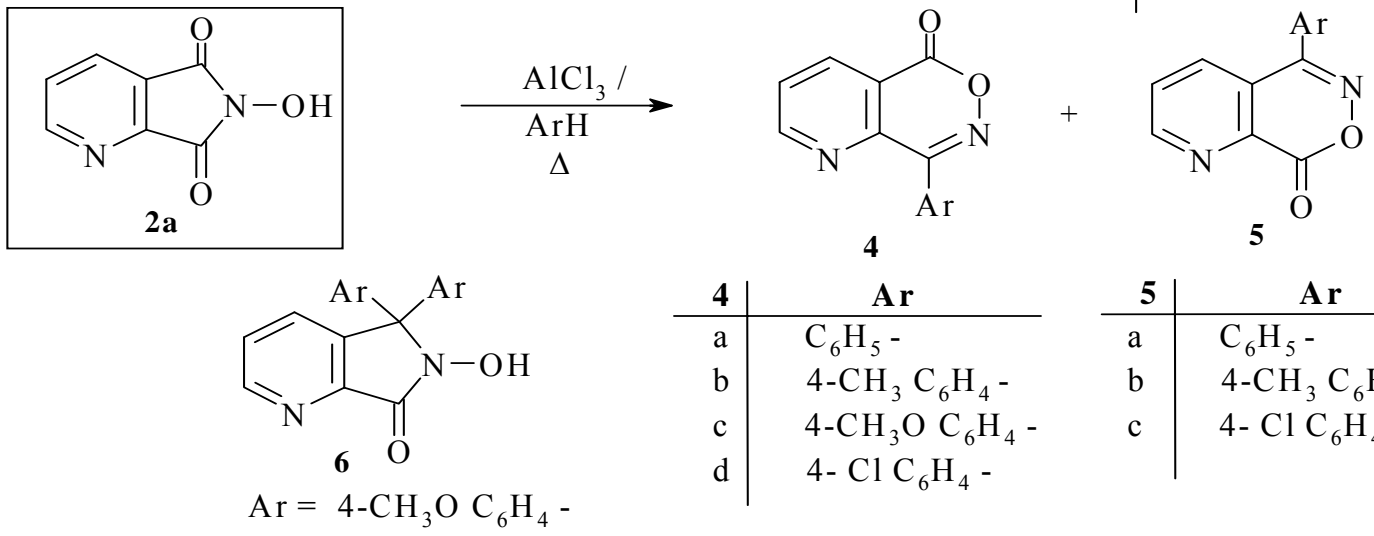

\begin{tabular}{c|c}
$\mathbf{5}$ & \multicolumn{1}{|c}{$\mathbf{A r}$} \\
\hline $\mathrm{a}$ & $\mathrm{C}_{6} \mathrm{H}_{5}-$ \\
$\mathrm{b}$ & $4-\mathrm{CH}_{3} \mathrm{C}_{6} \mathrm{H}_{4}-$ \\
$\mathrm{c}$ & $4-\mathrm{Cl} \mathrm{C}_{6} \mathrm{H}_{4}-$
\end{tabular}

Scheme 1. HHSS based on molecular rearrangements.

$\mathrm{N}$-Hydroxyphthalimide 1a reacts with phenyl magnesium bromide to give 1,1-diphenyl-3(phenylimino)-1,3-dihydrobenzo[c]furan 7 in $69 \%$ yield. ${ }^{4}$ The reaction mechanism might explained in terms of ring opening followed by Beckmann rearrangement, and then cyclization. 1a was used in synthesis of 1,4-phthalazinediones ${ }^{4} \mathbf{8 a}$,b in $80 \%$ yield via the reaction with hydrazines in acetic acid or ethanol. Fusion of $1 \mathrm{a}$ with hydrazines at $400^{\circ} \mathrm{C}$ gives phthalimides 9a,b in $62-79 \%$ yields. 
Pyrolysis of 2-phenyl-1,4-phthalazinedione $\mathbf{8 b}$ at $400^{\circ} \mathrm{C}$ gives $N$-phenylphathalimide $\mathbf{9 b}$ via ring contraction. Fusion of $N$-anilinophthalimide 10 at $200^{\circ} \mathrm{C}$ gives $\mathbf{8 b}$ via ring expansion. (Scheme 2).

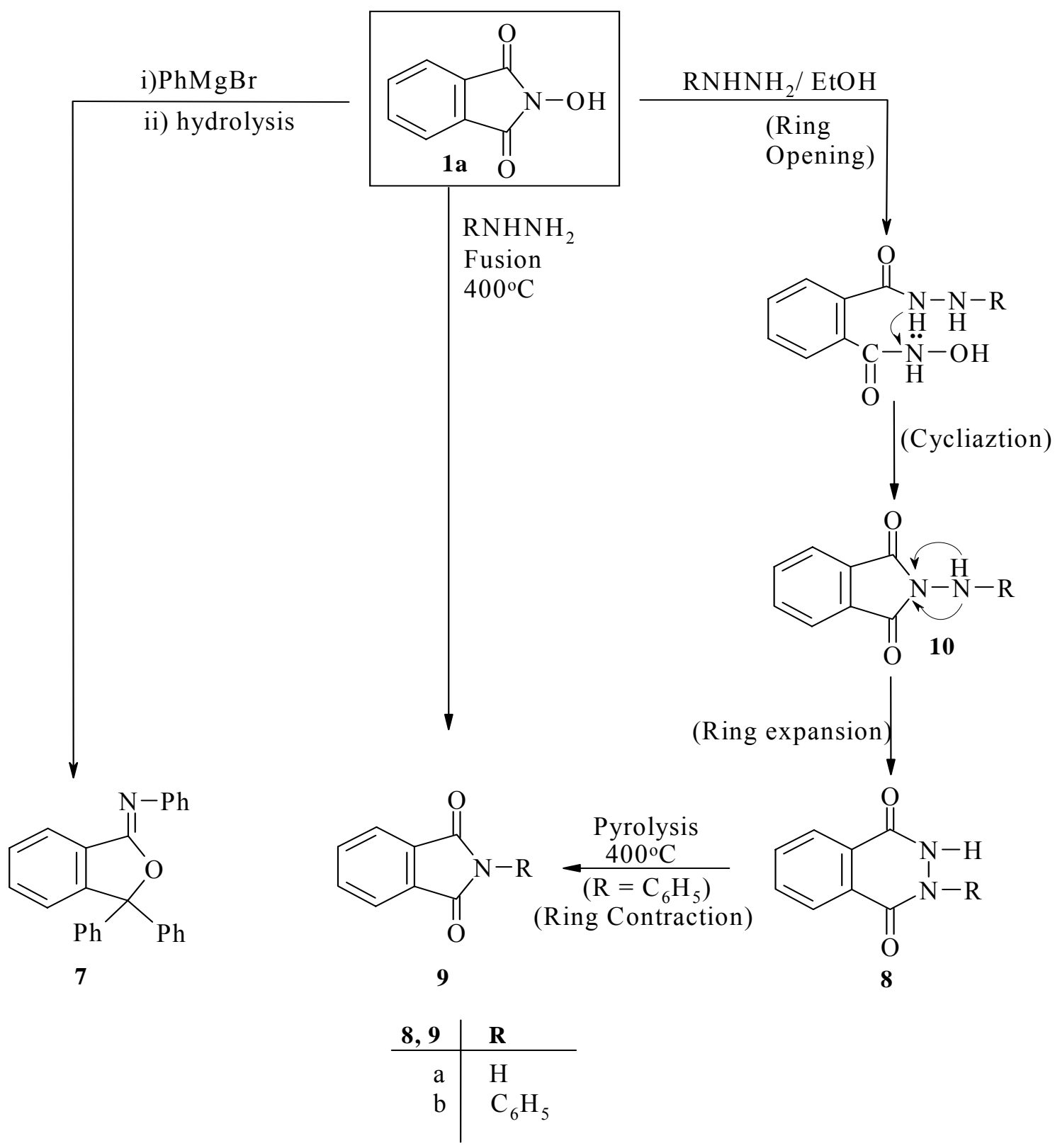

Scheme 2

$N$-Hydroxyphthalimide 1a reacts with ammonia and aromatic amines in ethanol under reflux to give $N$-arylphthalimides $9 \mathbf{a}-\mathbf{k}$ in $65-80 \%$ yields. ${ }^{4}$

Similarly, $N$-hydroxypyridine dicarboxylic imide 2 a reacts with aromatic amines at $250^{\circ} \mathrm{C}$ to give $N$-arylpyridine dicarboxylic imides 11a-d in $80-82 \%$ yields ${ }^{3}$ (Scheme 3 ). 

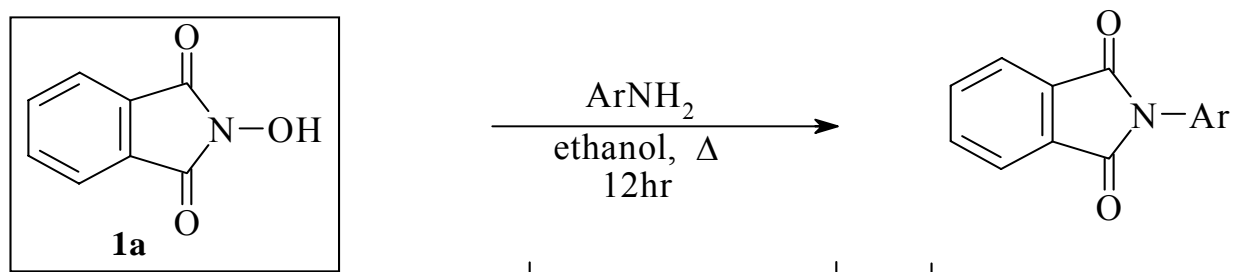

\begin{tabular}{l|l|c|l}
$\mathbf{9}$ & \multicolumn{1}{|c|}{ Ar } & $\mathbf{9}$ & \multicolumn{1}{c}{ Ar } \\
\hline $\mathrm{a}$ & $\mathrm{H}$ & $\mathrm{f}$ & $4-\mathrm{CH}_{3} \mathrm{OC}_{6} \mathrm{H}_{4}-$ \\
$\mathrm{b}$ & $\mathrm{C}_{6} \mathrm{H}_{5}$ & $\mathrm{~g}$ & $2-\mathrm{Cl} \mathrm{C}_{6} \mathrm{H}_{4}-$ \\
$\mathrm{c}$ & $2-\mathrm{CH}_{3} \mathrm{C}_{6} \mathrm{H}_{4}-$ & $\mathrm{h}$ & $4-\mathrm{Cl} \mathrm{C}_{6} \mathrm{H}_{4}-$ \\
$\mathrm{d}$ & $4-\mathrm{CH}_{3} \mathrm{C}_{6} \mathrm{H}_{4}-$ & $\mathrm{i}$ & $4-\mathrm{Br} \mathrm{C}_{6} \mathrm{H}_{4}-$ \\
$\mathrm{e}$ & $2-\mathrm{CH}_{3} \mathrm{O} \mathrm{C}_{6} \mathrm{H}_{4}-$ & $\mathrm{k}$ & $4-\mathrm{NO}_{2} \mathrm{C}_{6} \mathrm{H}_{4}-$
\end{tabular}
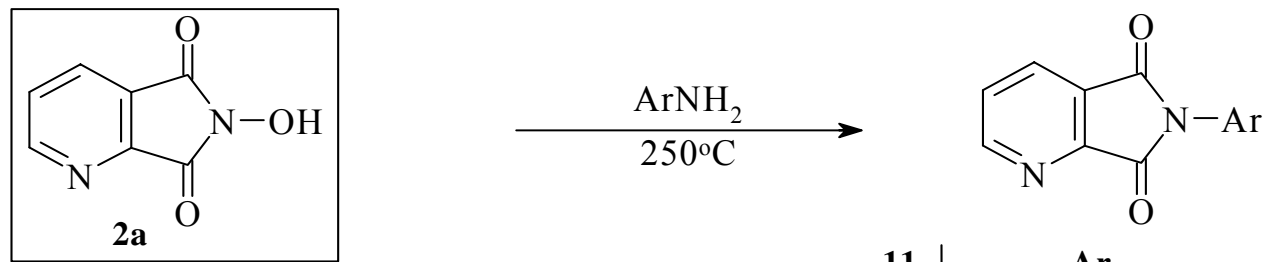

\begin{tabular}{c|l}
$\mathbf{1 1}$ & \multicolumn{1}{|c}{$\mathbf{A r}$} \\
\hline $\mathrm{a}$ & $\mathrm{C}_{6} \mathrm{H}_{5}$ \\
$\mathrm{~b}$ & $4-\mathrm{CH}_{3} \mathrm{C}_{6} \mathrm{H}_{4}-$ \\
$\mathrm{c}$ & $4-\mathrm{CH}_{3} \mathrm{O} \mathrm{C}_{6} \mathrm{H}_{4}-$ \\
$\mathrm{d}$ & $4-\mathrm{Cl} \mathrm{C}_{6} \mathrm{H}_{4}-$
\end{tabular}

\section{Scheme 3}

The reaction probably takes place via the following mechanism (Scheme 4).<smiles>CC1=C(C)C(=O)N(O)C1=O</smiles>

1a, 2 a<smiles>CC1=C(C)C(=O)C(=N)NC1=O</smiles>

12
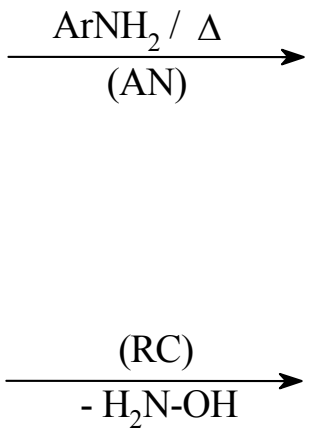

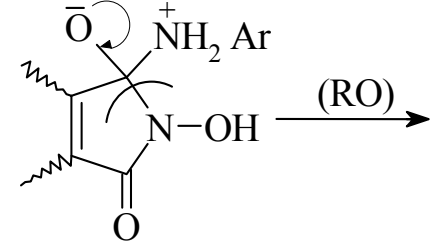<smiles>CC1=C(C)C(=O)N([Al])C1=O</smiles>

9, 11

Scheme 4. ANRORC mechanism. 


\section{2. $N$-Arylsulphonyloxy cyclic imides}

$N$-Arylsulphonyloxy cyclic imides $\mathbf{1 b}, \mathbf{c}$ and $\mathbf{2 b}$ were used as building blocks in synthesis of condensed pyrimidines.

$\mathrm{N}$-Arylsulphonyloxyphthalimides $\mathbf{1 b}, \mathbf{c}$ react with aromatic amines to give diarylurea derivatives 13a-d, which upon pyrolysis yield, 3-aryl-1,2,3,4-tetrahydroquinazoline-2,4-diones 14a-d in 40-60\% yields (Scheme 5).
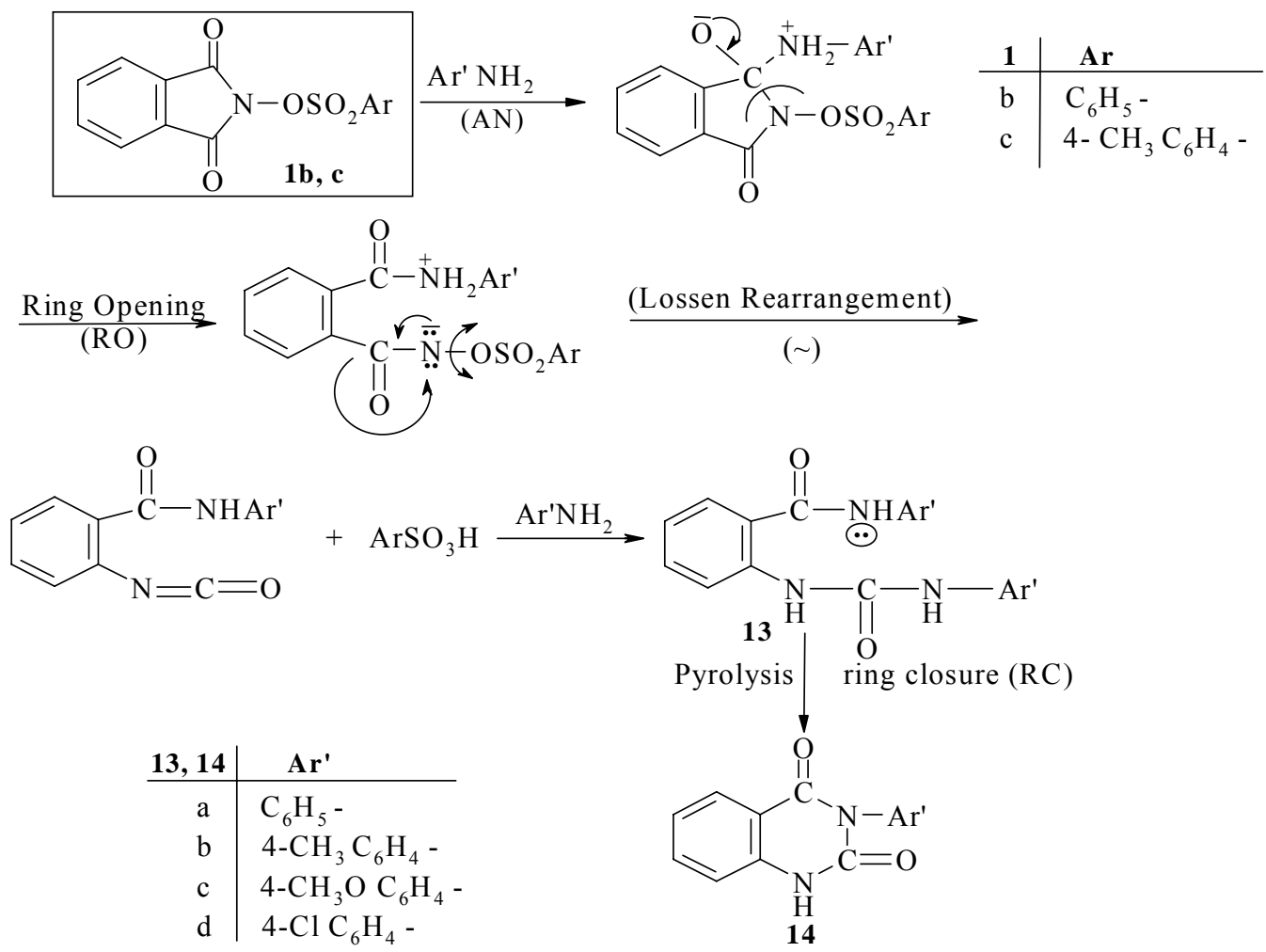

\section{Scheme 5}

The reaction of $N$-benzenesulphonyloxy-pyridine2,3-dicarboxylic imide $\mathbf{2 b}$ with ammonia, hydroxylamine and hydrazine now constitutes a facile one- pot synthesis of pyrido[3,2d]pyrimidine-2,4-dione derivatives 15a-c in 63-74\% yields. ${ }^{5}$

Our synthetic strategy depends on nucleophilic addition (AN) of amines followed by ring opening $(\mathrm{RO})$, then Lossen rearrangement $(\sim)$ followed by ring closure $(\mathrm{RC})$ i.e. (ANRO $\sim \mathrm{RC})$ ring transformation (Scheme 6). 

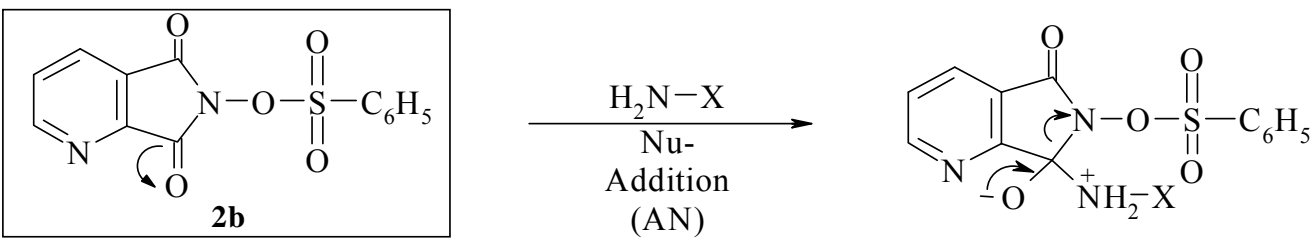

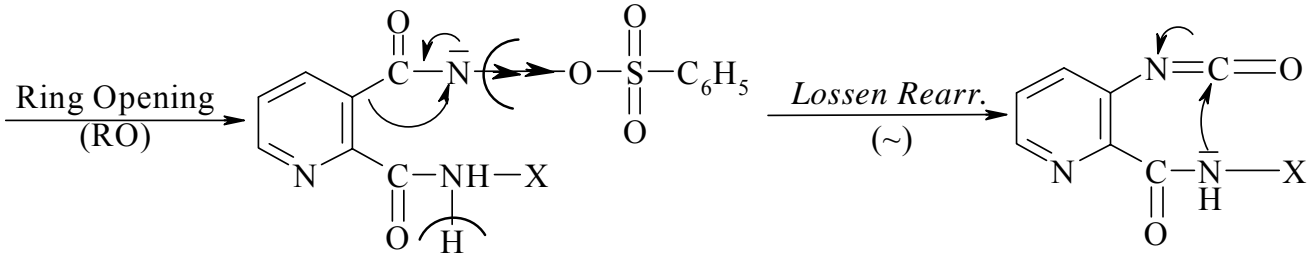

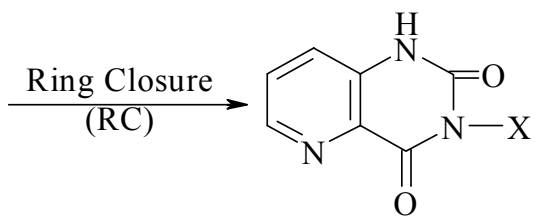

\begin{tabular}{c|c}
$\mathbf{1 5}$ & $\mathbf{X}$ \\
\hline $\mathrm{a}$ & $\mathrm{H}$ \\
$\mathrm{b}$ & $\mathrm{OH}$ \\
$\mathrm{c}$ & $\mathrm{NH}_{2}$
\end{tabular}

Scheme 6. ANRO RC type ring transformation.

Recently pyrido[2,3-d]pyrimidines have been prepared from pyrimidinones via regioselective cyclocondensation reaction. ${ }^{6}$

\section{Spirooxiranes as building blocks}

Spirooxiranes 16, and 17 offer new synthetic routes to target spiro, and condensed heterocycles via one-pot cycloaddition reaction.

(16)

Figure 2. Spirooxiranes

\subsection{2-Aryl-1-oxaspiro $(2,5)$ octa-4-ones}

2-Aryl-1-oxaspiro(2,5)octa-4-ones 16a,b our favorite building blocks, were prepared in the usual way. ${ }^{7}$ Compounds 16a,b were reacted with $\mathrm{CS}_{2}$ in alkaline medium to produce 4-aryl-1-oxa-3thiospiro(4,5)deca-2-thione-6-ones 18a,b in 50-60\% yields. The reaction takes place via cycloaddition reaction (Scheme 7). 


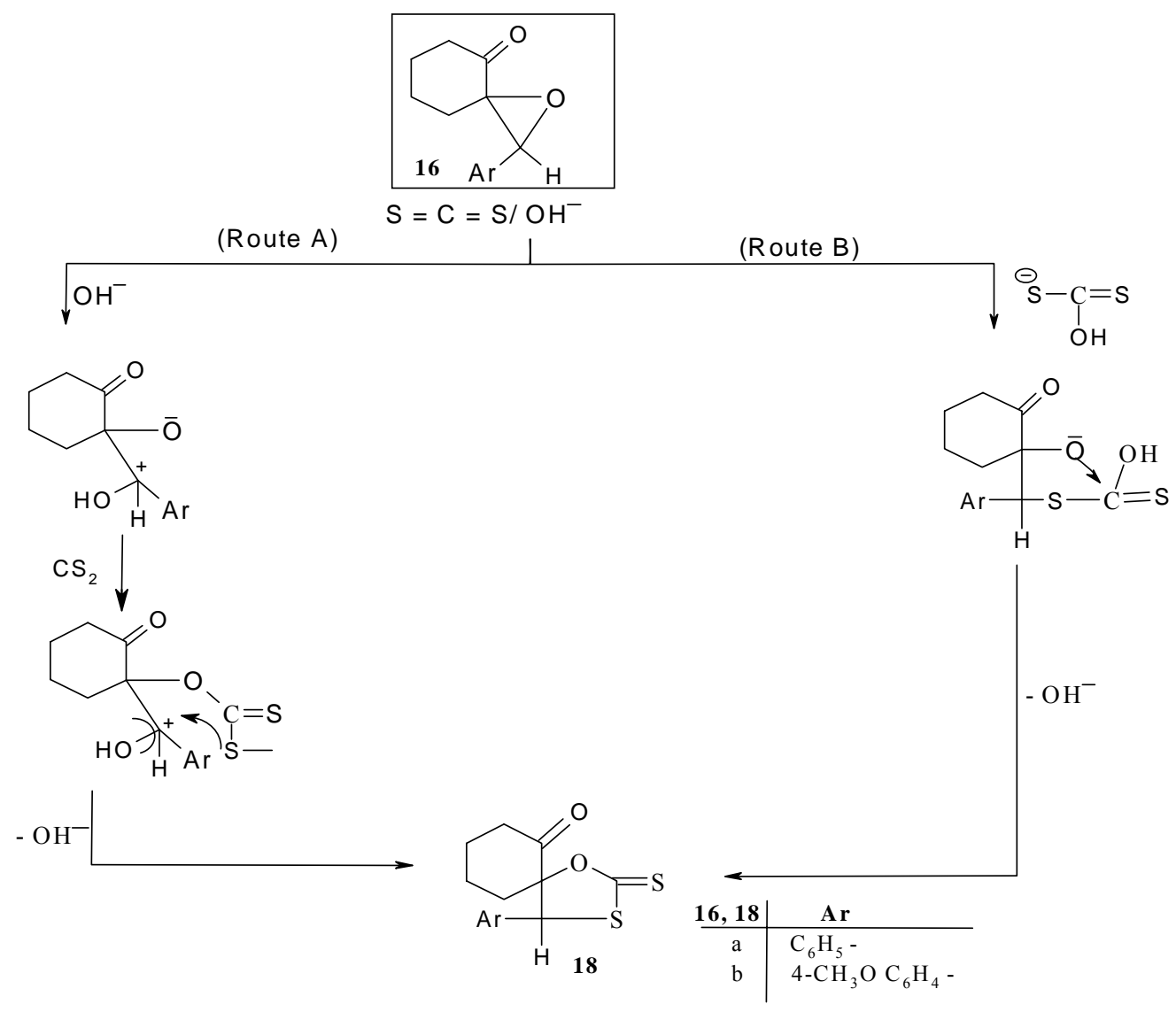

Scheme 7. HHSS based on cycloaddition reaction.

Compounds 16a,b reacted with benzoyl azide in benzene under reflux to give 6,7-dihydro3,4-diarylbenz-1,3-oxazin-2-ones 19a,b via a novel $(4+2)$ cycloaddition reaction in which spirooctanone acts as 1,4-dipole to give intermediate adduct 20 followed by opening of the oxirane ring with elimination of a molecule of water to give the final product $19 a, \mathbf{b}^{8}$ (Scheme 8). 


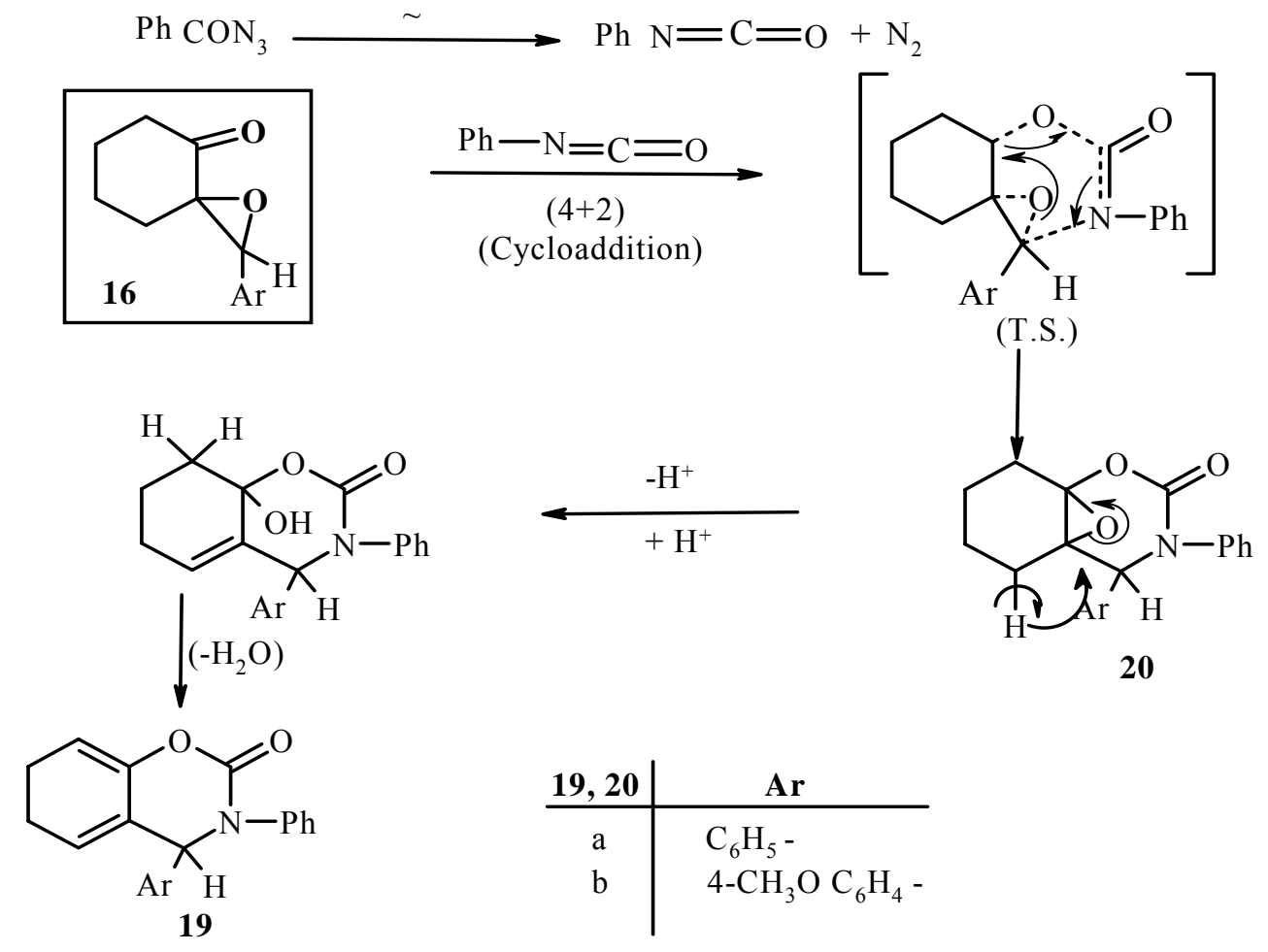

Scheme 8. HHSS based on (4+2) cycloaddition reaction.

When 2-(p-anisyl)-1-oxaspiro(2,5)octa-4-one $\mathbf{1 6 b}$ was heated at $150^{\circ} \mathrm{C}$ for one $\mathrm{hr}$, bisspirodioxane 21 was obtained in 30\% yield, ${ }^{8}$ via radical dimerization reaction (Scheme 9).
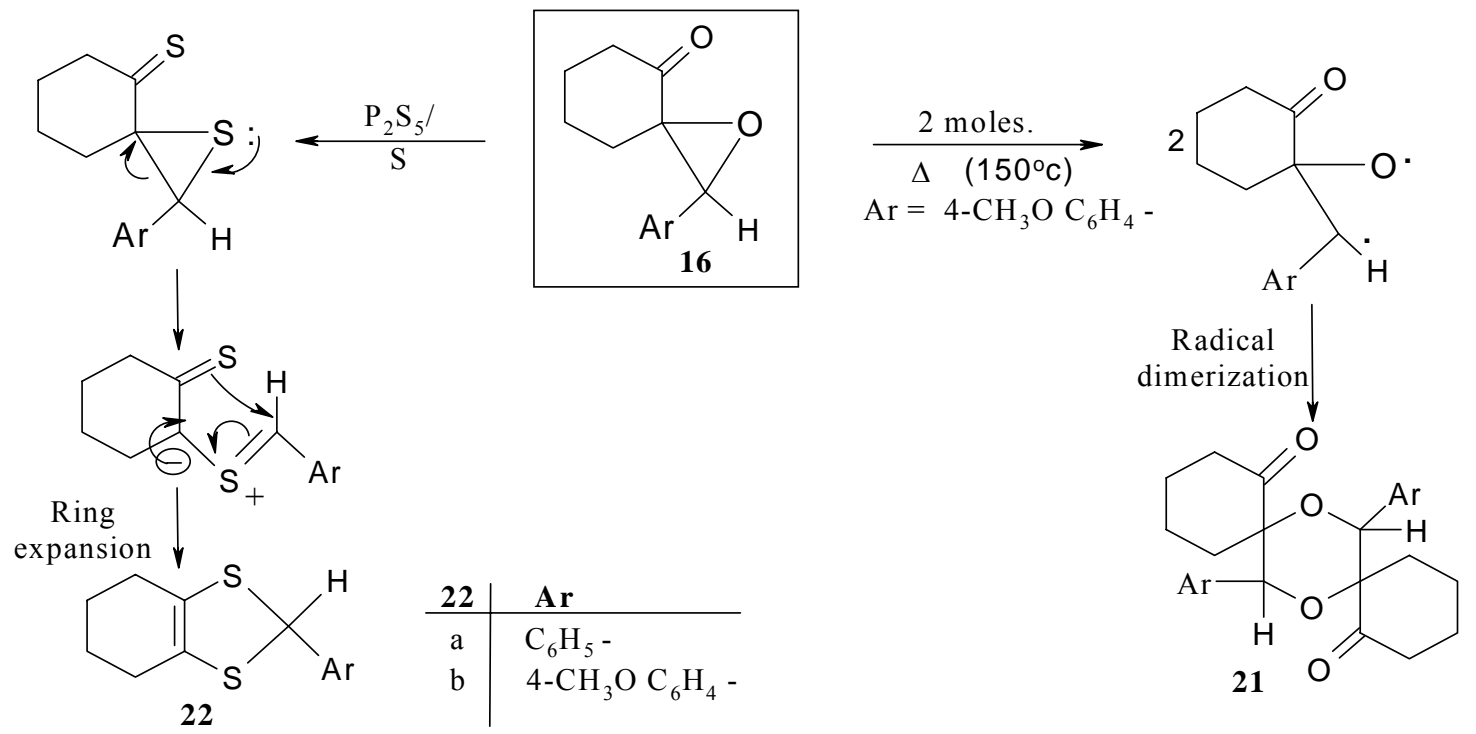

Scheme 9. HHSS based on Ring expansion and radical dimerization reactions. 
Thiation of 16a,b with $\mathrm{P}_{2} \mathrm{~S}_{5}$ in the presence of sulfur powder yielded 2-aryl-1,2,3,4tetrahydrobenzo $(5,6-d)-1,2$,-dithiols $22 a$, b in $45-50 \%$ yields. ${ }^{8}$

\section{2. $3^{`}$-Aryl-(3`H)(2H)-spirooxirane (2',3)-benzopyran-4-ones}

3'-Aryl-(3'H)(2H)-Spirooxirane(2',3)benzopyran-4-ones 17a-c were prepared in (70-75\%) yields via the reaction of the corresponding arylmethylene benzopyran-4-ones 23a-c with $\left(\mathrm{H}_{2} \mathrm{O}_{2} / \mathrm{OH}^{-}\right){ }^{9}$

Spirooxiranes 17a-c reacted with carbon disulfide in the presence of ethanolic sodium hydroxide to give-4-aryl-2-thioxo-(4H)-thieno [3,4-b]-benzopyran-4-ones 24a-c in 50 - 60\% yields. (Scheme 10).
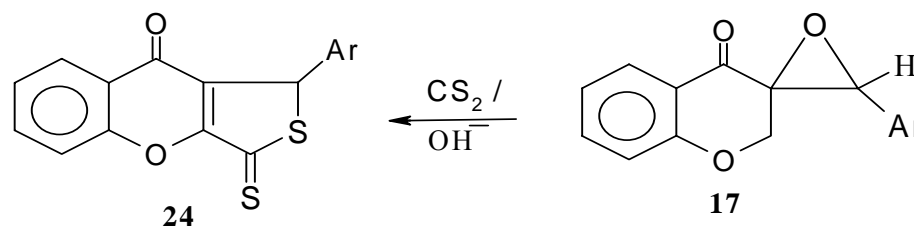

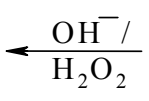

Ar

\begin{tabular}{c|c}
$17,23,24$ & Ar \\
\hline a & $4-\mathrm{CH}_{3} \mathrm{C}_{6} \mathrm{H}_{4}-$ \\
b & $4-\mathrm{CH}_{3} \mathrm{O} \mathrm{C}_{6} \mathrm{H}_{4}-$ \\
c & $4-\mathrm{Cl} \mathrm{C}_{6} \mathrm{H}_{4}-$
\end{tabular}

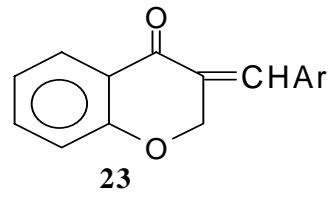

Scheme 10. HHSS based on cycloaddition reaction.

\section{Oxazines as Building Blocks}

We have developed a new approach to the synthesis of condensed nitrogen heterocycles e.g., (quinazolines, pyridopyrimidines, isoquinolines), based on using condensed oxazines 3-5 in the (ANRORC) ring transformation.

\subsection{2, 3-Benzoxazin-1-one}

4-(4-Methylphenyl)-2,3-benzoxazin-1-one $3 \mathbf{b}$ was used as a precursor in a facile one-pot new synthetic route to isoquinolines. When $\mathbf{3 b}$ reacted with (methoxycarbonyl) methylenetriphenyl phosphorane 25a in boiling toluene in the presence of triethylamine, methyl 1-(4methylphenyl)4-oxo-3H-isoquinoline-3-carboxylate 26a was obtained in $74 \%$ yield ${ }^{10}$. Similarly, treatment of $\mathbf{3 b}$ with $\mathbf{2 5 b}$ afforded $\mathbf{2 6 b}$ in $68 \%$ yield. Treatment of $\mathbf{2 6 a}$ with benzoyl chloride or acetic anhydride in pyridine gave the expected O-benzoyl, and O-acetyl derivatives 27a,b in 72\% and 75\% yields, respectively. The reaction takes place via the (ANRORC) mechanism ( Scheme 11). 

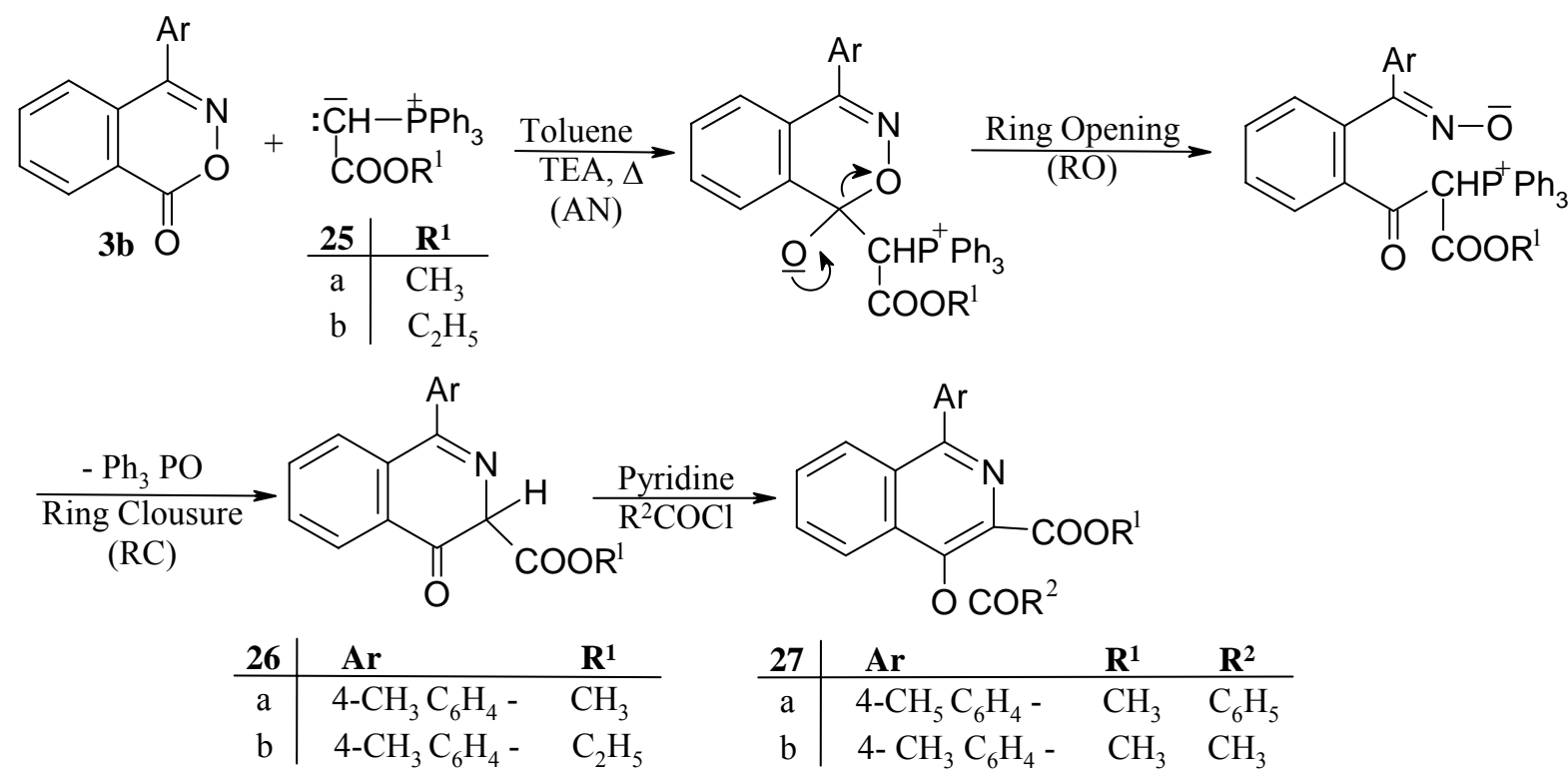

Scheme 11. HHSS based on ANRORC-ring transformation.

Treatment of oxazinone $\mathbf{3 b}$ with an equimolar amount of keto ylide 28a, for 3 days gave in addition to isoquinolone derivative 29a (38\%), a new ylide 30 a in $22 \%$ yield.

Reaction of $\mathbf{3 b}$ with $\mathbf{2 8 b}$ only takes place in a molar ratio 1:2. Isoquinoline derivative $\mathbf{2 9 b}$ was obtained in only 12\% yield; beside,2,3-diacetyl-4-(4-methylphenyl)- $\alpha$-naphthol 31 (33\%) and 2-acetyl-3-methyl-5-(4-methylphenyl)-benzocylcohepten-1-one 32 (22\%) ${ }^{10}$ (Scheme 12).

\subsection{Benzoxazines and pyrido-oxazines}

4-Arylphthalazine-1-ones 33a-c were obtained from the reaction of 4-aryl-2,3-benzoxazin-1ones 3a,b,d with hydrazine hydrate in glacial acetic acid in $(80-90 \%)$ yields ${ }^{11}$ (Scheme 13).

8-Arylpyrido[2,3-d][1,2] oxazin-5-ones 4a-d, reacted with hydrazine in acetic acid to give 8-arylpyrido[2,3-d]pyridazin-5(6H)-ones ${ }^{11}$ 34a-d in $81-89 \%$ yields.

The isomeric 5-arylpyrido[3,2-d][1,2]oxazin-8-ones 5a-c, under the same reaction conditions, gave 5-arylpyrido[2,3-d] pyridazine $^{11} 8(7 H)$ ones 35a-c in $62-75 \%$ yields. (Scheme 13). 


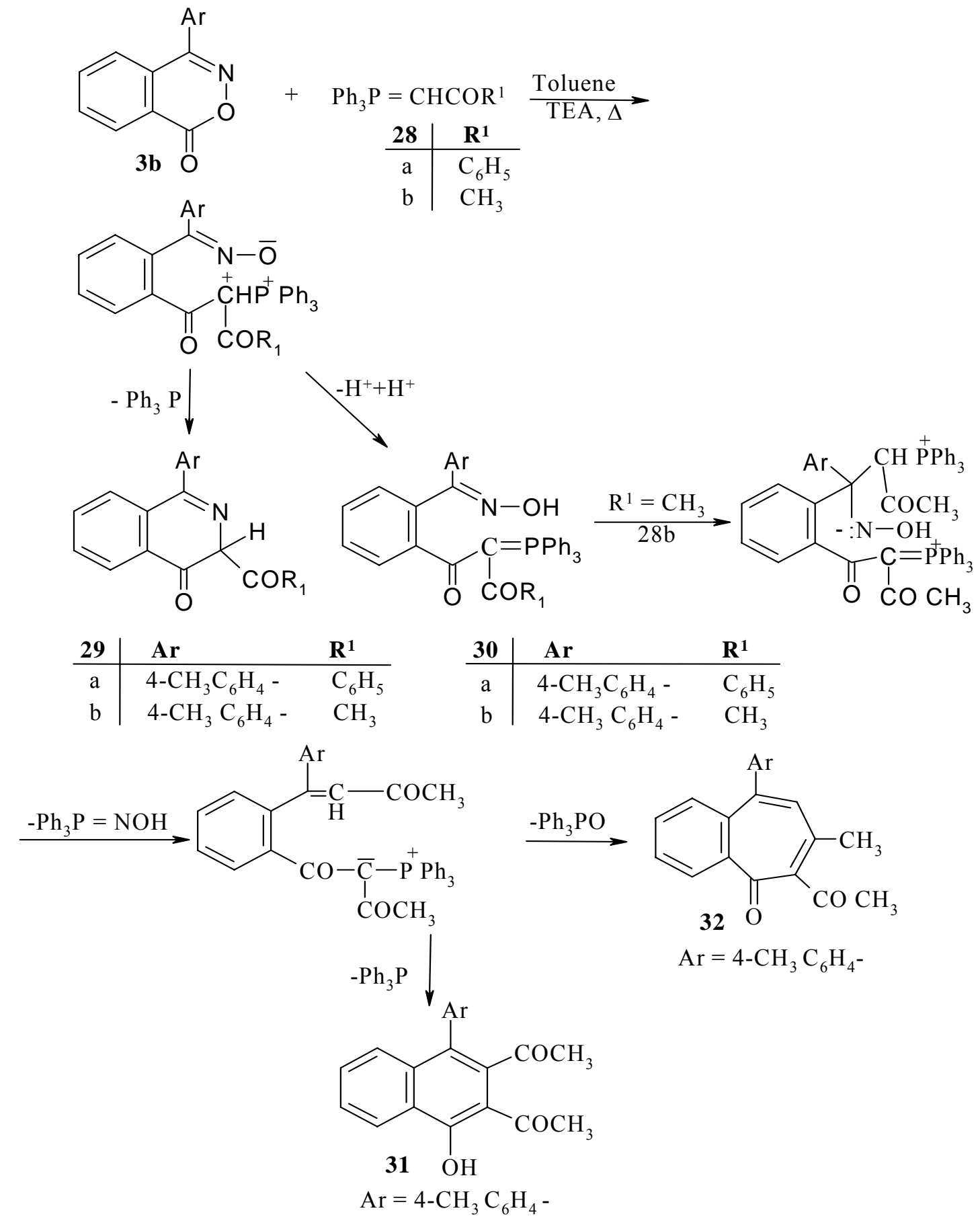

Scheme 12 
<smiles>O=c1onc(Br)c2ccccc12</smiles>

$3 \mathbf{a}, \mathbf{b}, \mathbf{d}$<smiles>O=c1onc([Al])c2ncccc12</smiles><smiles>O=c1onc(Br)c2cccnc12</smiles>
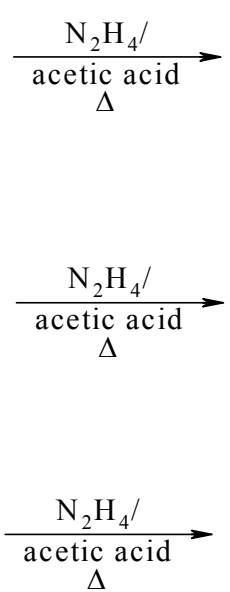<smiles>O=c1[nH]nc(Br)c2ccccc12</smiles>

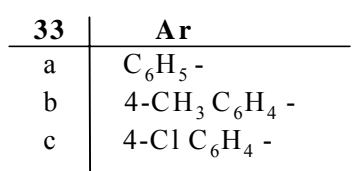<smiles>O=c1[nH]nc(Br)c2ncccc12</smiles>

\begin{tabular}{c|l}
34 & \multicolumn{1}{|c}{$\mathbf{A r}$} \\
\hline $\mathrm{a}$ & $\mathrm{C}_{6} \mathrm{H}_{5}-$ \\
$\mathrm{b}$ & $4-\mathrm{CH}_{3} \mathrm{C}_{6} \mathrm{H}_{4}-$ \\
$\mathrm{c}$ & $4-\mathrm{CH}_{3} \mathrm{O} \mathrm{C}_{6} \mathrm{H}_{4}^{-}$ \\
$\mathrm{d}$ & $4-\mathrm{Cl} \mathrm{C}_{6} \mathrm{H}_{4}-$
\end{tabular}<smiles>O=c1[nH]nc(Br)c2ncccc12</smiles>

Scheme 13. HHSS based on ANRORC ring transformation.

\section{Pyridopyridazines as building blocks}

8-Arylpyrido[2,3- $d]$ pyridazin-5(6H)-ones 34a,b were used as building blocks in synthesis of 6aryl-1,2,4-triazolo[3,4-b]pyrido[2,3-d]pyridazines $\mathbf{3 6 a , b}$ in $68-71 \%$ yields via the intermediate compounds 37a,b and 38a,b in a three-step synthesis. ${ }^{11}$

Similarly, 5-arylpyrido[2,3-d]pyridazine- $8(7 H)$-ones 35a,b were used in synthesis of 6aryl-1,2,4-triazolo[4,3- $d]$ pyrido[2,3- $d]$ pyridazines $39 a, b$ in $82-86 \%$ yields via intermediate compounds 40a,b and 41a,b.

Our work towards the synthesis of 36a,b and 39a,b is shown (Scheme 14) in which the key step involves cyclocondensation of the hydrazine derivatives $\mathbf{3 8}$ and $\mathbf{4 1}$ with formic acid at 40 $45^{\circ} \mathrm{C}$. ${ }^{11}$ 


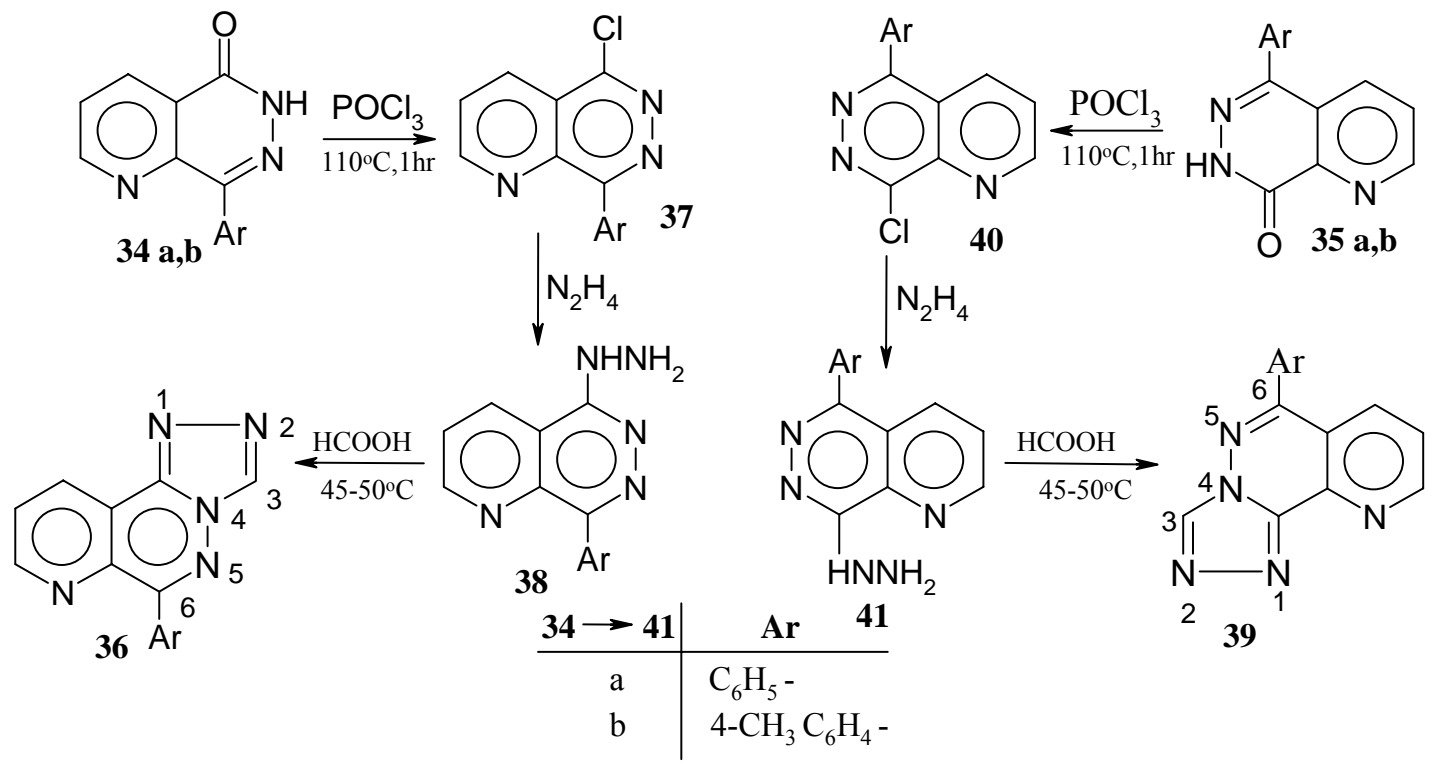

Scheme 14. Three-step synthesis.

\section{Oxazolones as building blocks}

Oxazoles are well known building blocks ${ }^{12-15}$. We have been interested in developing efficient synthetic routes to imidazoles, tetrazoles,1,3,5-oxadiazines, and 1,2,4-tetrazines based on 1,3oxazolones 42a-l as building blocks (Figure 3).

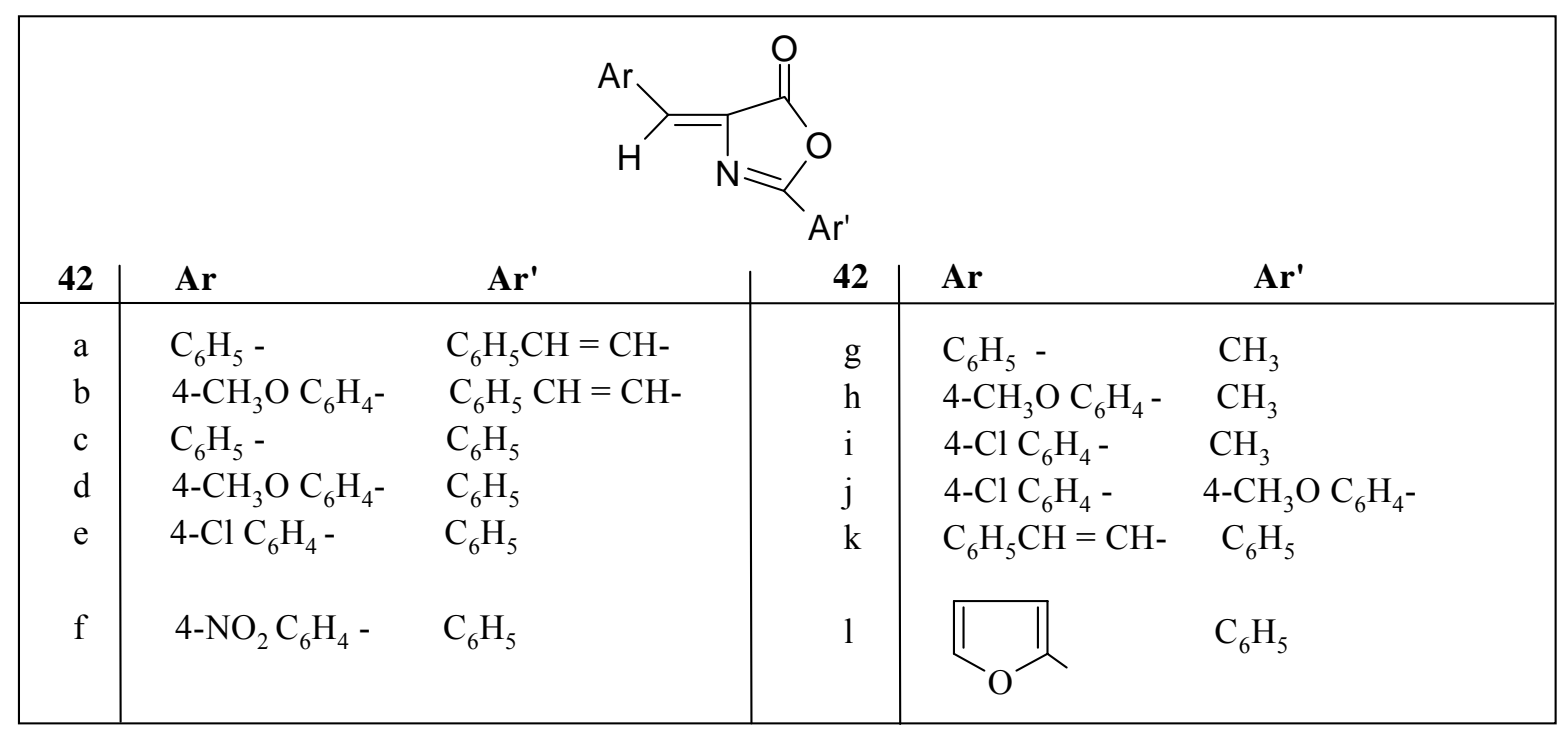

Figure 3 
4-Arylidene-2-styryl-5(4) oxazolones 42a,b reacted with $p$-aminobenzoic acid in refluxing ethanol to give 4-arylidene-1-[4'-carboxypheny]-2-styryl-5-oxo-imidazoles 43a,b in 85-95\% yields. $^{16}$

The reaction takes place via nucleophilic addition (AN) followed by ring opening $\mathrm{RO}\left(\mathrm{C}_{5}{ }^{-}\right.$ O- fission) then ring closure (RC) i.e. ANRORC ring transformation.

Oxazolone derivatives 42c-i were used in synthesis of $\alpha$-tetrazolycinnamic acid derivatives ${ }^{17} \mathbf{4 4 a - g}$ in $70-75 \%$ yields via $\left(\mathrm{C}_{2}-\mathrm{O}\right)$ fission (Route-b).

2-Arylidene-4-aryl-6-oxo-1,3,5-oxadiazines 45a-d were obtained in 45-55\% yields from oxazolones 42b, j, k, l via two-step synthesis ${ }^{18}$ (Scheme 15).

Hydrazinolysis of 4-anisylidene-2-styryl-5(4H) oxazolone 42b with phenylhydrazine gave 1, 2, 4-triazine derivative 46 via ANRORC mechanism (Scheme 15).

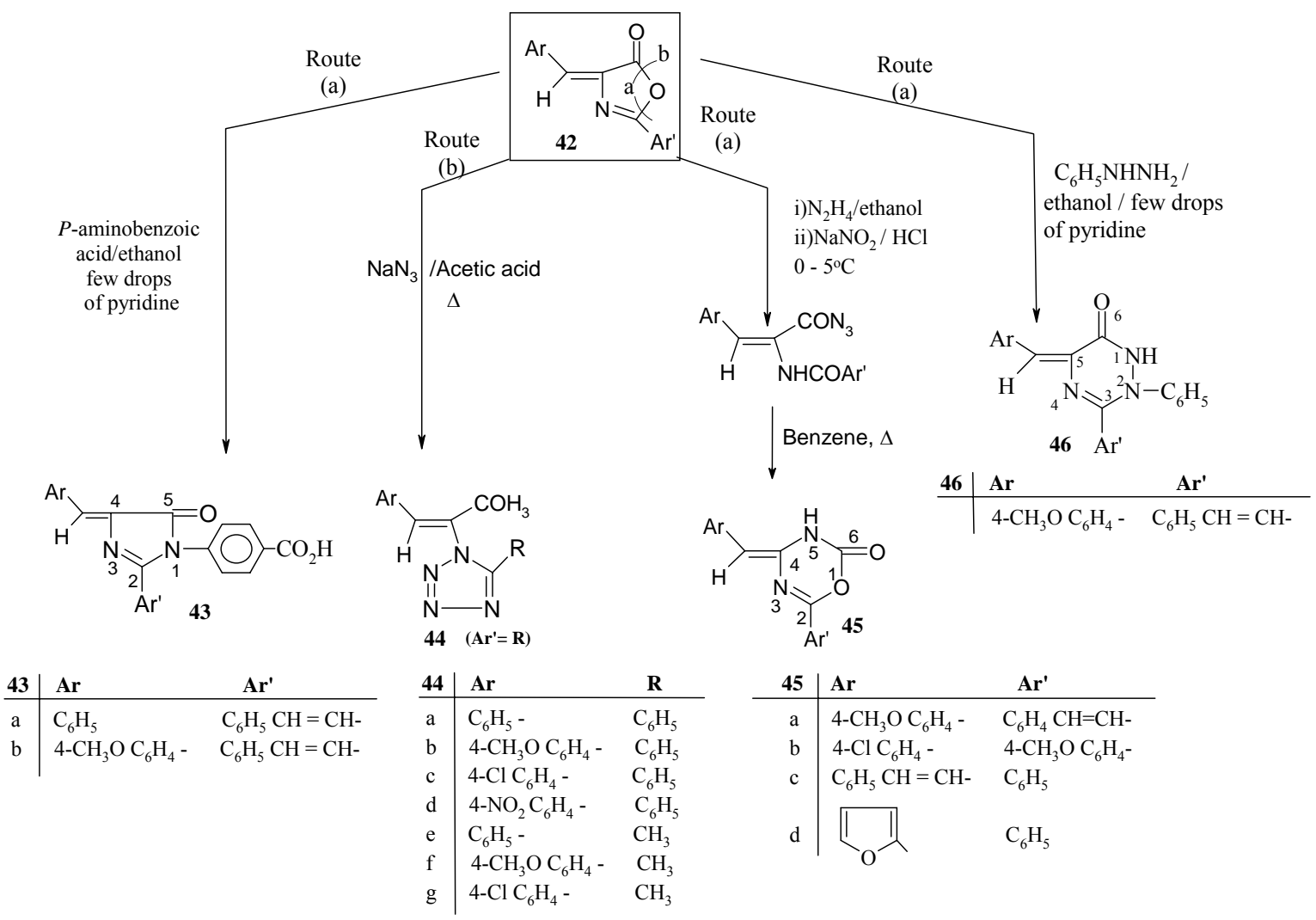

Scheme 15

\section{Uracils as building blocks}

6-Azidouracils 47a reacted with phosphorus ylides 25a,b in refluxing ethylacetate to give a mixture of (7-triphenylphosphoranylidene) pyrimido[5,4-d]-pyrrole-6- $(5 H)$-one 48a in 48\% yield, and pyrimido[5,4-d]pyrrole-6-one 49a in 24\% yield (Scheme 16). When 6-azido-1,3- 
dimethyluracil 47b was treated with an equimolar amount of 25a under the same experimental conditions, products 48b (28\%) and 49b (13\%) and 1,3,6,8-tetramethylpyrimido[5,4-g] pteridine-2,4,5,7 tetrone $\mathbf{5 0}(17 \%)$ were obtained. ${ }^{19}$

6-Azidouracil 47a reacted with benzoylmethylenetriphenylphosphorane to give 6phenylpyrrolo[3,2-d] pyrimidine 51 in $63 \%$ yield according to the mechanism shown in Scheme 16.

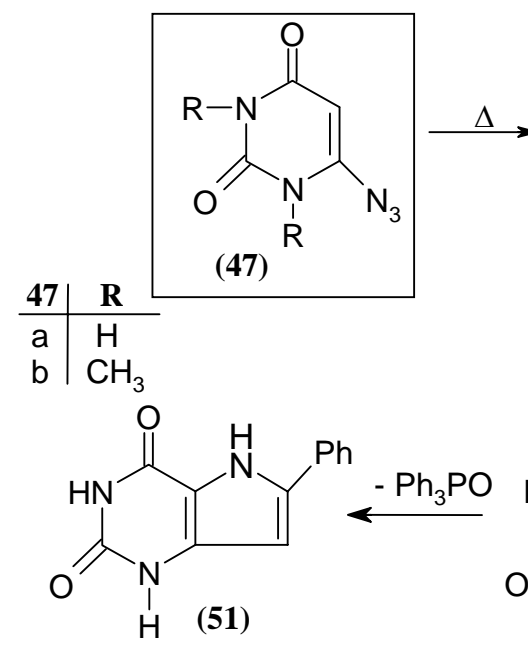

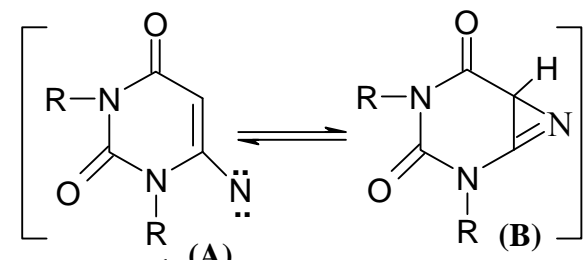

(A)

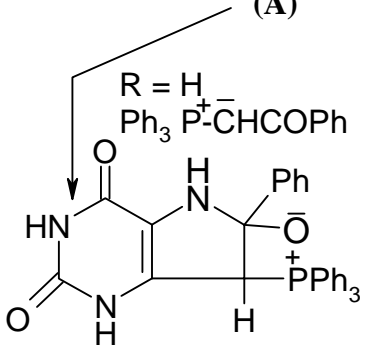
(B)

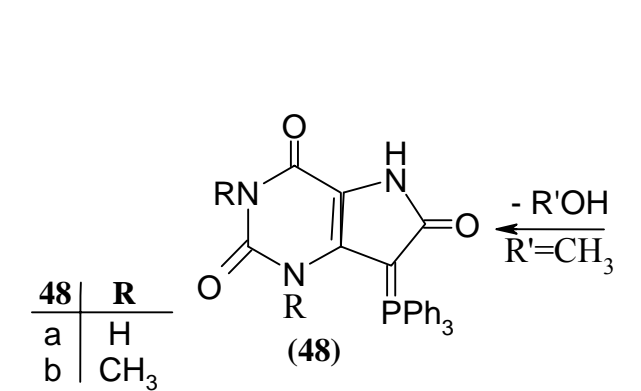

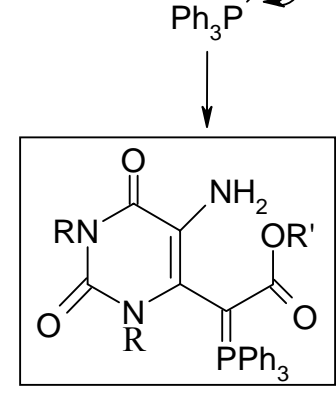<smiles>Cn1c2c(c(=O)n(C)c1=O)Nc1c(n(C)c(=O)n(C)c1=O)N2</smiles>

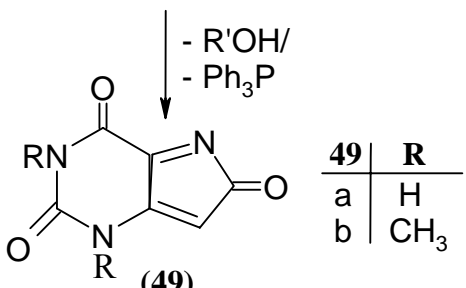

(50)

\section{Scheme 16}

\section{Pyridazinones as building blocks}

Treatment of 4-cyano-5,6-difur-2'-yl-2H-pyridazine-3-one 52 with an equimolar amount of vinyltriphenylphosphonium bromide in a mixture of $\mathrm{LiOH} / \mathrm{H}_{2} \mathrm{O} / \mathrm{EtOH}$ yielded 2,3-difur-2 yl-4cyano-5,8-oxazolo[2,3-b]1,2-dihydropyridazine 53 (63\%), beside 5-amino-3,4-difur-2'-yl- 
pyrano[2,3-c]1,2-dihydropyridazine $54(23 \%){ }^{20,21}$ The reaction takes place according to the mechanism shown (Scheme 17).

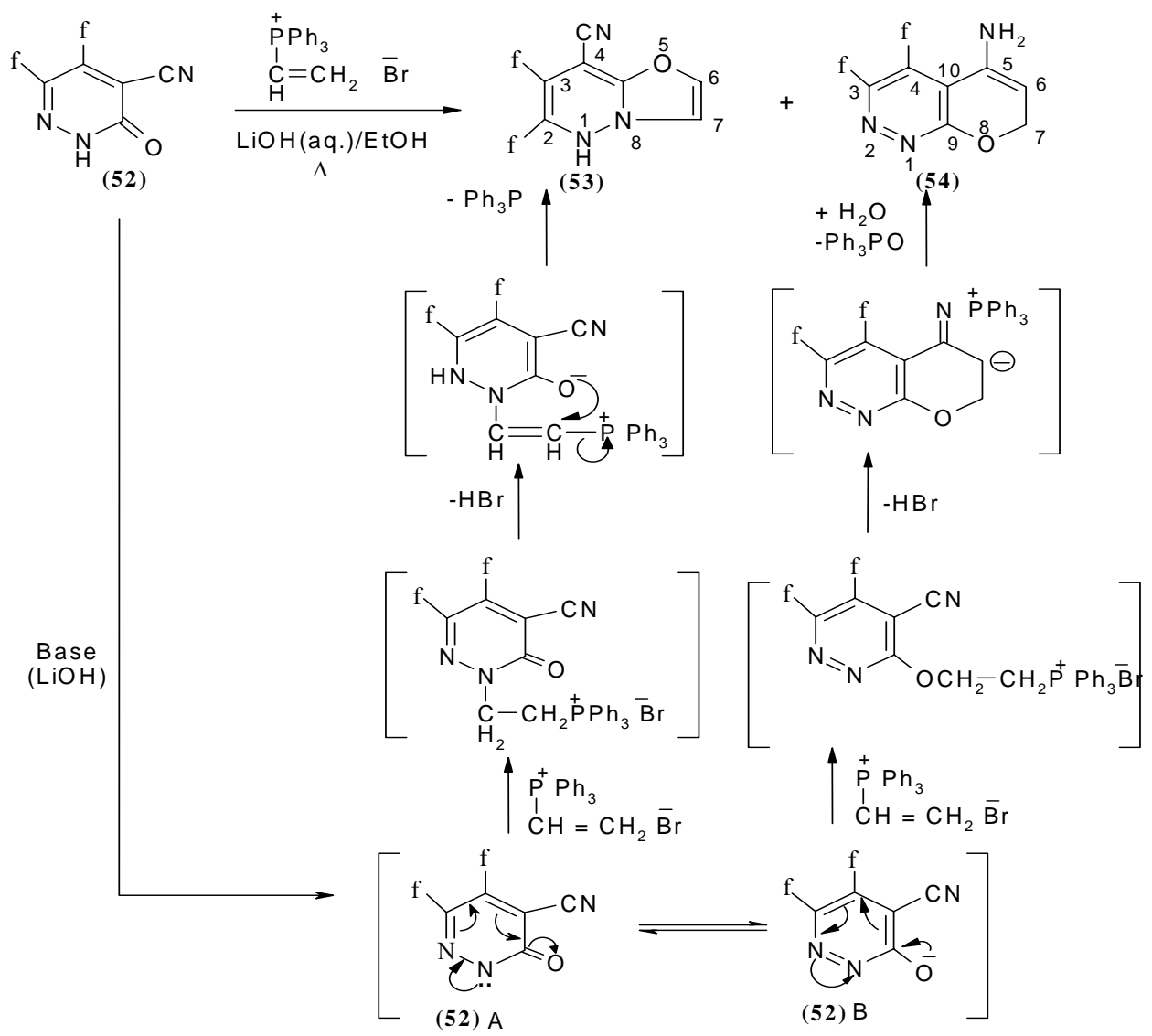

\section{Scheme 17}

Reaction of 52a with an excess of methylidinetriphenylphosphorane 55a in the presence of lithium hydride in refluxing DMF, for $30 \mathrm{hr}$ afforded, 5-amino-3,4-difur-2'yl-furano[2,3-c]1,2dihydro-pyridazine $\quad \mathbf{5 6 a} \quad(22 \%)$ and 5-methyl-3,4-difur-2'yl-6H-isopyrrolo[2,3c]1,2dihydropyridazine 57a (43\%) ${ }^{20,21}$ (Scheme 18).

Similarly, 52a reacts with 55b under the same reaction conditions to give a mixture of $\mathbf{5 6} \mathbf{b}$ (22\%), and 57b (47\%). The reaction takes place according to the following mechanism (Scheme 18). 


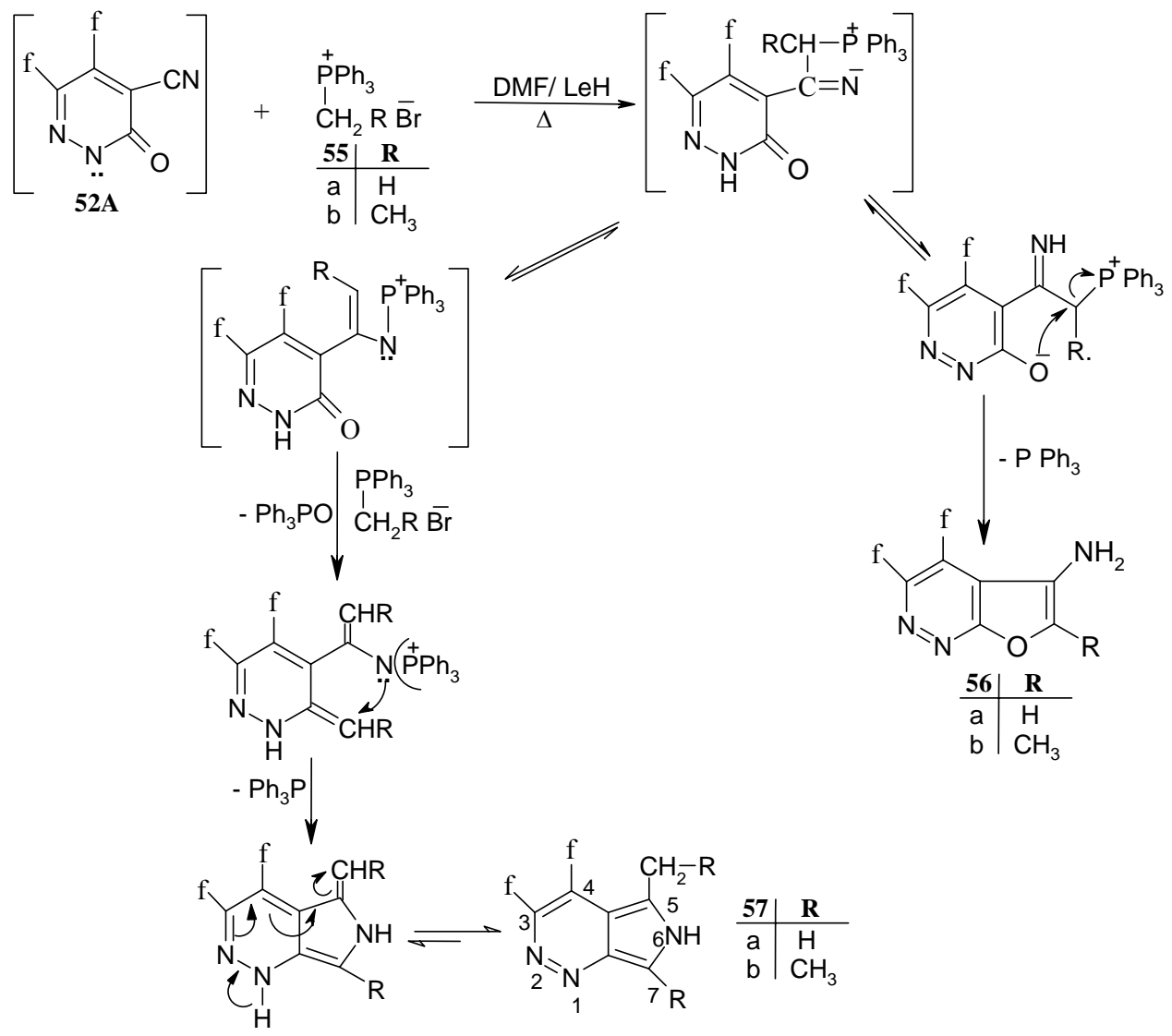

Scheme 18

\section{Benzopyran and benzothiopyran derivatives as building blocks}

Arylmethylenebenzopyrans and arylmethylenebenzothiopyrans were used as versatile building blocks in one-pot reactions for new synthesis of target heterocyclic systems in reasonable yields e.g. Benzopyranopyrazoles, benzothiopyranopyrazoles, benzopyranopyrimidines, benzothiopyranopyrimidines, benzopyranopyridines, benzothiopyranopyridines, benzopyranopyran, benzothiopyranopyran.

This building strategy depends on cyclocondensation reactions with different reagents. Reaction of 3-arylmethylene-3,4-dihydro[1]benzopyran-4-ones 23b-e with hydrazine or phenylhydrazine in refluxing glacial acetic acid gave 2-acetyl-3-aryl-2,3,3a,4-tetrahydro(4H)[1]benzopyrano[4,3-c]pyrazoles 59a-d (71-88\%), and 2-phenyl-3-aryl-2,3,3a,4-tetrahydro-(4H)[1]benzopyrano[4,3-c]pyrazoles 60a-d (65-73\%), respectively.

Similarly, 3-arylmethylene-3,4-dihydro[1]benzothiopyran-4-ones 58a,b reacted with hydrazine or phenylhydrazine under the same experimental conditions to give 2-acetyl-3-aryl2,3,3a,4-tetrahydro-(4H)[1]benzothiopyrano[4,3-c]pyrazoles 59e,f (80-82\%) and 2-phenyl-3- 
aryl-2,3,3a,4-tetrahydro-(4H)[1]benzothiopyrano[4,3-c]pyrazoles $\mathbf{6 0 e , f}(65-82 \%)$, respectively (Scheme 19).

Reaction of 23a-d and 58a,b with guanidine hydrochloride in ethanol and $\mathrm{NaOH}$ yielded 2amino-4-aryl-3,4-dihydro-(5H)[1] benzopyrano[4,3-d]-pyrimidines 61a-d(65-75\%), and 2-amino-4aryl-3,4-dihydro- $(5 H)[1]$ benzothiopyrano[4,3-d] pyrimidines 61e,f $(60 \%)$, respectively (Scheme 19).

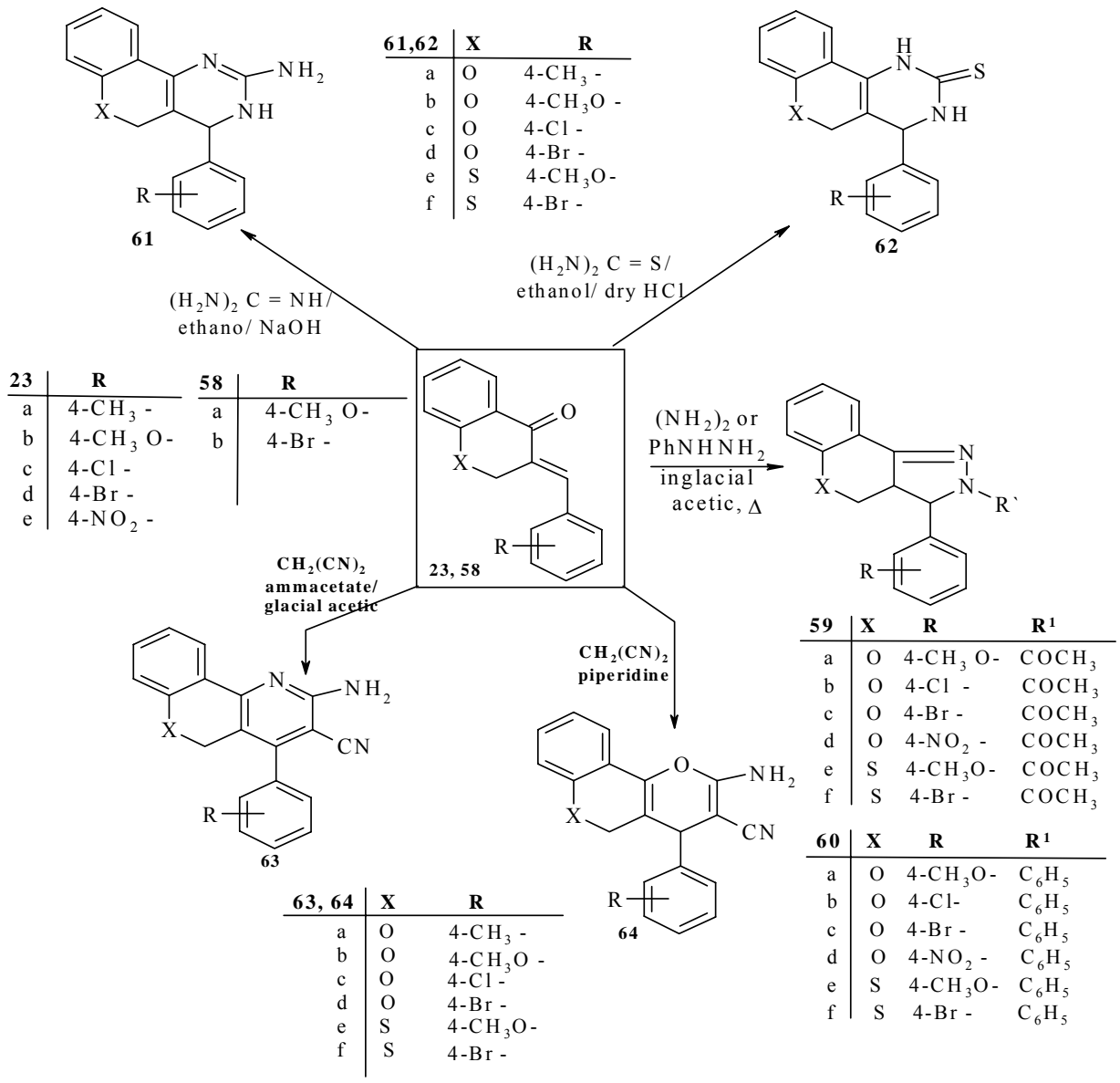

Scheme 19. HHSS based on cyclocondensation.

Also, compounds 23a-d and 58a,b react with thiourea in ethanol and dry $\mathrm{HCl}$ gas to give 4-aryl-1,2,3,4-tetrahydro-(5H)[1]benzopyrano[4,3-d]pyrimidine-2-thioxo 62a-d 70-85\%, and 4aryl-1,2,3,4-tetrahydro- $(5 H)[1]$ benzothiopyrano[4,3-d]pyrimidine-2-thioxo $\quad \mathbf{6 2 e , f} \quad 61-65 \%$, respectively.

2-Amino-4-aryl-(5H)[1]benzopyrano[4,3-b]pyridine-3-carbonitriles 63a-d 60-71\%, and 2amino-4-aryl- $(5 H)[1]$ benzothiopyrano[4,3-b]pyridine-3-carbonitriles $\quad 63 \mathbf{e}, \mathbf{f} \quad 67-75 \%$ were obtained from the reaction of 23a-d and 58a,b with malononitrile, ammonium acetate in refluxing glacial acetic acid (Scheme 19). 
Compounds 23a-d and 58a,b reacted with malononitrile in a mixture of ethanol and piperidine to give 2-amino-4-aryl- $(4 H),(5 H)[1]$ benzopyrano[4,3-b]pyrano carbonitriles 64a-d, $67-81 \%$ and 2-amino-4-aryl- $(4 H),(5 H)[1]$ benzothiopyrano[4,3-b]pyrano carbonitriles 64e,f 65 $72 \%$ respectively, ${ }^{9}$ (Scheme 19$)$.

\section{Acknowledgments}

The author wishes to thank his colleagues who have contributed to the topics discussed in this lecture specially Prof. Abdou W., National research center, Cairo, Egypt for her valuable synthetic contribution.

\section{References}

1. Fahmy A. F. M., Aly, N. F., Nada, A., Aly, N. A. Bull. Chem. Soc. Jpn. 1997, 50, 2678.

2. Baddar F. G. Fahmy A. F. M., Aly N. F. J. Chem. Soc., Perkin Trans.1 1973, 2448.

3. Fahmy A. F. M., Sauer J., Youssef M. S. K., Abdel Halim M. S., Hassan M. A., Synth. Commun. 1998, 28, 2871.

4. Fahmy A. F. M., Aly N. F., Orabi M. O. Bull. Chem. Soc. Jpn. 1978, 51, 2148.

5. Fahmy A. F. M., Youssef M. S. K., Abdel-Halim M. S., Hassan, M. A., Sauer, J. Heterocycles 1986, 24, 2201.

6. Quiroga J., Insuasty H., Insuasty B., Abonia R., Cobo J. Sanchez A. Nogueras, M. Tetrahedron 2002, 58, 4837.

7. Yousef N. M., Gad, F. A., Fahmy A. F. M., Amine M. S., Sayed H. H. Phosphorus, Sulfur and Silicon 1996, 117, 11.

8. Yousef N. M., Fahmy A. F. M., Amine M. S., Gad F. A, Sayed H. H. Phosphorus, Sulfur and Silicon 1998, 133, 13.

9. Hammam A. G., Fahmy A. F. M., Amr A. E., Mohamed, A. M. Ind. J. Chem. 2003, 42(B), 1985.

10. Abdou W. M., Fahmy A. F. M., Kamel A. A. Eur. J. Org. Chem. 2002, 1696.

11. Fahmy A. F. M., Sauer J., Youssef M. S. K., Abdel-Halim, Hassan, M. A., $1^{\text {st }}$ Ibn Sina Symposium on Heterocyclic Chemistry, Organized by Aim Shams University and Institute of Organic Chemistry, Technical University, Vienna, Cairo, Egypt, 1986, 9-11 Dec.

12. Arenal I., Bernabe M., Alvarez F., Izquiredo M. L., Penades S. J. Heterocyclic, Chem.1983, 20, 607.

13. Argyropoulos N. G., Coutouli-Argyropoulou, E. J. Heterocyclic Chem. 1984, 21, 1397.

14. Costa M., Chiusoli G. P., Tafurelli D., Dalnionego, G. J. Chem. Soc., Perkin Trans. 1. 1998, 1541.

15. Swaleh, S., Liebscher J. J. Org. Chem. 2002, 67, 3184. 
16. Fahmy A. F. M., Orabi M. O. A. Ind. J. Chem. 1972, 10, 961.

17. Awad W. I., Fahmy A. F. M., Sammour A. M. A., J. Org. Chem. 1965, 30, 2222.

18. Awad W. I., Fahmy A. F. M., Cand. J. Chem. 1968, 46, 2207..

19. Abdou W. M., Fahmy A. F. M., Kamel A. A. Heteroatom Chem. 2002,13, 357.

20. Abdou W.M., Ganoub N. A., Fahmy A. F. M., Shady A. M., Heteroatom Chem., 2005, 16, 56.

21. Abdou W. M., Ganoub N. A., Fahmy A. F. M., Shady A. M., Phosophorus, Sulfur,and Silicon 2005, 16 (in press). 